\title{
Creep and Fatigue Crack Growth in Tubes at High Temperatures
}

\author{
M. RÖDIG, M. PFAFFELHUBER, F. SCHUBERT and \\ H. NICKEL \\ Institut für Reaktorwerkstoffe, Kernforschungsanlage, Jülich, \\ P.O.B. 1913, D-5170 Jülich, FRG
}

\section{ABSTRACT}

Fracture mechanics experiments have been performed with several types of standard specimens and thick walled tubes made of Alloy 800 . The aim was to demonstrate the transferability of creep and fatigue crack growth data at high temperatures.

In the creep crack growth experiments, steam reformer tubes were provided with an external $360^{\circ}$-crack in circumferential direction. The loading con-

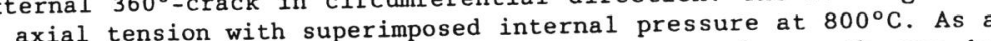
dition was axial tension with supe found, that creep crack growth can be described by means of the energy rate integral $C^{*}$.

The fatigue crack growth experiments have been performed with a thick The fatigue crack growth exper $180^{\circ}$ surface crack. It was loaded at a walled tube with an external $180^{\circ}$-surface crack. frequency of $5 \mathrm{~Hz}$ in four polnt the base of several approx

\section{INTRODUCTION}

In order to demonstrate the transferability of fracture mechanics data in In order to demonstrate the transferability of freep crack growth (CCG) the high the and fatigue cras. Beside standard specimens (1" CT, 1/2" CT, 1/2" CCP) thick walled tubes were tested in some experiments.

Seven tubes of $120 \mathrm{~mm}$ o.d. and $10 \mathrm{~mm}$ w.th. were tested before in fatigue crack growth experiments with pure tension. The results of these experiments were published elsewhere (Rodig et al., 1987) and shall not be considered in this paper. The work of this paper deals with the following experiments :

- CCG: tubes of $120 \mathrm{~mm}$ o.d. and $10 \mathrm{~mm}$ w.th. with an external circum $800{ }^{\circ} \mathrm{C}$. 
- FCG: tubes of $197 \mathrm{~mm}$ o.d. and $23.5 \mathrm{~mm}$ w.th. with an external circumferential crack $\left(180^{\circ}\right)$, loaded in four point bending at $550^{\circ} \mathrm{C}$.

For both groups, additional reference experiments were performed with $1 / 2^{\text {"CT-, }} 1$ "CT-, and $1 / 2^{\text {"CCP-specimens. }}$

\section{MATERIAL}

ial for all experiments was the austenitic alloy X NiCrAlTi 3220 (Alloy 800) with the chemical composition (wt\%):
c : 0.073
$\begin{array}{lr}\text { Fe: } & \text { Bal. } \\ \text { Ti: } & 0.31\end{array}$
$\mathrm{Ni}: \quad 30.7$
r: 20.05
Al: 0.25
Mn: 0.6
Si: 0.3

The standard specimens were taken from sheet material. The crack plane orientation was T-L in accordance with ASTM-E 399.

For the calculation of $C^{\star}$, the constants $B$ and $n$ of Norton's creep law

$$
\dot{\epsilon}=B \sigma^{\mathrm{n}}
$$

were required. They were obtained from supplementary creep experiments as $\mathrm{n}=5.3$ and $\mathrm{B}=1.9 \cdot 10^{12} \mathrm{~h}^{-1} \mathrm{MPa}^{-\mathrm{n}}$
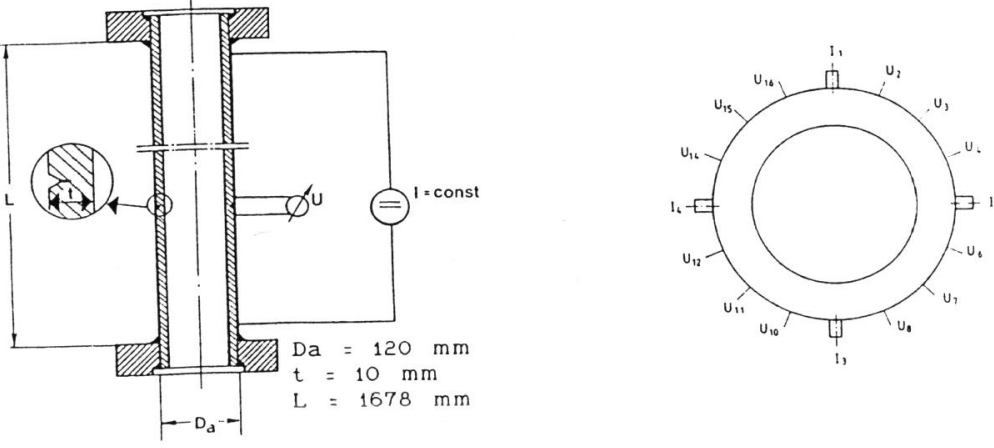

Fig. 1. Reformer tube with

circumferential crack connections for $D C P D$

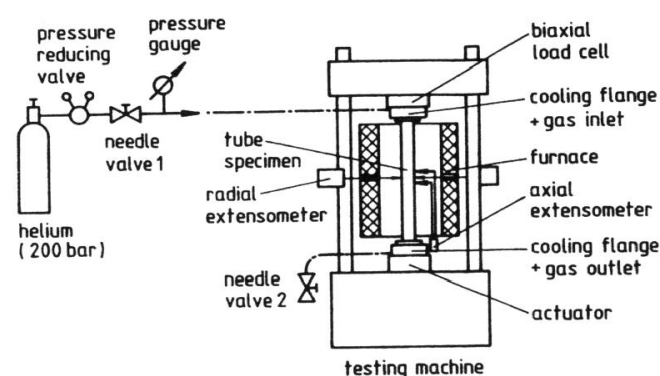

Fig. 2. Schematic diagram of the testing system

\section{GREEP CRACK GROWTH EXPERIMENTS}

\section{Experimental Details}

The standard specimen tests were carried out in an electromechanica testing machine. The syst The reformer tubes of $120 \mathrm{~mm}$ o.d. and $10 \mathrm{~mm}$ w.th. were provided with a circumferential notch of 2.5 to $3 \mathrm{~mm}$ depth (cp, perack at room temperature up to $a / t=40 \%$.

Por For testing the steam reformer tubes, a servo-hydralar furnace was use $500 \mathrm{kN}$ maximum load and with a through the top and bottom of the fur(cp. Fig. 2). The tubes wering cylinders were protected against excessive nace. Load cells and The cooling flanges also served to introduce the heat by cooling internal pressure by heedle valve 2 represents an artificial leak cer upon failure of thery low flow rate. This mode of operation ensures a and is adjusted the pressure reducer and simultaneously compen(ates for small leaks in the pressure system.

The The nique. tubes. The measuring current of $80 \mathrm{~A}$ was applied at four points near the flanges (cp. Fig. 1). Voltage was measured at 16 positions across the circumference. The DCPD-technique was calibrated using a duy tub with was cumferential saw cut. The location of the potential moni optimized with regard to sensitivity and noise margin.

\section{Calculation of the loading parameters $\mathrm{K}_{\mathrm{I}}$ and $\mathrm{C}^{*}$}

The $K_{I}$ values for the CT specimens were calculated from the equation

$$
\mathrm{K}_{\mathrm{I}}=\underset{\mathrm{DW}}{\mathrm{F}} \mathrm{P}
$$

Wher where $F$ is the load, $D$ the specis function $Y$ was taken frem

the circumThe tube specimens exhibited non-uniform crack shape was idealized, and the ference. For the calculation of ${ }^{I}$ crack front was made.

C* was calculated using the equation (Riedel and Wagner, 1984):

$$
\mathrm{C}^{*}=\boldsymbol{\eta} \dot{\mathrm{v}} \sigma_{\text {net }}
$$

With $=$ net section stress, and $\dot{r}=$ crack opening displacement rate. With ${ }^{\sigma}$ net ${ }^{2}$ net ferential flaws, no solutions for $\eta$ are given in literature. For this reason, finite-element simulations were carried out for this specimen geomeary loaded by internal pressure $p$ and superimposed tensile stress 
(Rödig et al., 1988). The $C^{*}$ values were determined for the maximum initial crack length $a=3.6 \mathrm{~mm}$, the minimum initial crack length $a=2.6 \mathrm{~mm}$, an for an average crack length $a=3.05 \mathrm{~mm}$ from the line integral. $\eta$ was determined by equating the numerically obtained value the opening measureThe values of were used from those point.

As in the case of standard specimens, $\boldsymbol{\eta}$ only depends on the crack depth to As in the cack depth by $30 \%$ causes a change in $\boldsymbol{\eta}$ y 3 . was used for the calculation of $C^{*}$ in the CCG experiments with tubes.

\section{Results}

Two tests were performed on steam reformer tubes to study creep crack growth. In both cases, the tensile load was superimposed by a constan internal pressure. The load conditions were:

- int. pressure: 40 bars, tensile stress: $5 \mathrm{MPa}$ (tube no. AYJ-1.3)

- int. pressure: 50.4 bars, tensile stress: $26 \mathrm{MPa}$ (tube no. BCD-EN1) During the experiment the crack length was continuously measured by means of the DC potential method. For the tube AYJ-3.1 the variation in crack length at the radial positions $U_{1}$ and $U_{13}$ which show the largest amount of crack growth, is shown in the left part of Fig. 3. Up to about 200 hours, the crack growth velocity decreases and then constant. The right part of Fig. In view of the decreasing crack growth velocity, it does not appear meaningful to plot da/dt vs. KI. Moreover, a calculation that crack growth time ${ }^{1}$ accor daldt lated $C^{*}$-values at the positions $U_{1}$ and $U_{13}$ of tube no. AYJ-3.1.
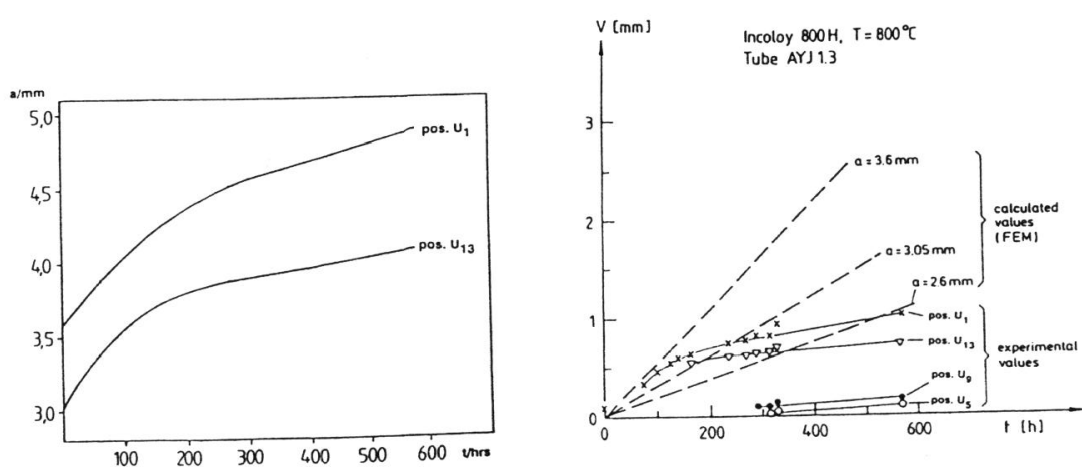

Fig. 3. Progression of crack depth (left) and crack opening displacement (right) at two positions of the reformer tube

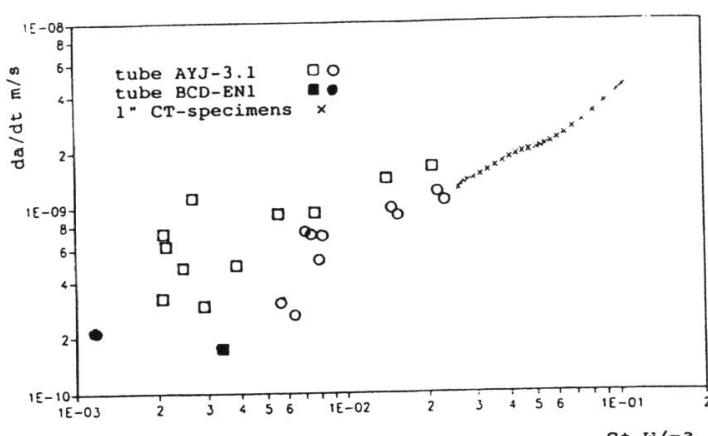

Fig. 4. Crack growth velocity da/dt as a function of $\mathrm{C}^{*}$ for reformer tubes and CT specimens

For the tube BCD-EN1 again an evaluation was possible at two circumferenFor the tube $B C D$ it appeared only meaningful to average $C^{*}$ over the entire test period in view of the measuring accuracy. The results of this tube are represented by the filled symbols of Fig. 4.

The CCG-results for the reformer tubes and for the CT-specimens are in good agreement. Therefore it may be assumed that the $C^{*}$ concept is suitable for describing the creep crack growth in Alloy 800 at $800^{\circ} \mathrm{C}$

\section{FATIGUE CRACK GROWTH EXPERIMENT}

\section{Experimental Details}

The standard specimens were tested in a servohydraulic testing system of $100 \mathrm{kN}$ maximum load. The specimens were heated by means of a high frequency generator.

The tubes of $197 \mathrm{~mm} \mathrm{o.d.} \mathrm{and} 23.5 \mathrm{~mm}$ w.th. were tested in 4 point bending on a stress plate of. The stressing was produced by a servohydraulic actuator of $100 \mathrm{kN} \max$. load. The temperature of $550^{\circ} \mathrm{C}$ was achieved by heating depth, produced becimens were provided with

As in the case of the CCG experiments (comp. to Chapter 3.1), the crack de used, and the potential drop was measured at 24 positions around the circumference of the tube.

\section{Calculation of $\Delta \mathrm{K}_{\mathrm{I}}$}

For the standard specimens, $K_{I}$ again was calculated according to equ.(2) with Y from Schwalbe (1980) for the CCP-specimens. 


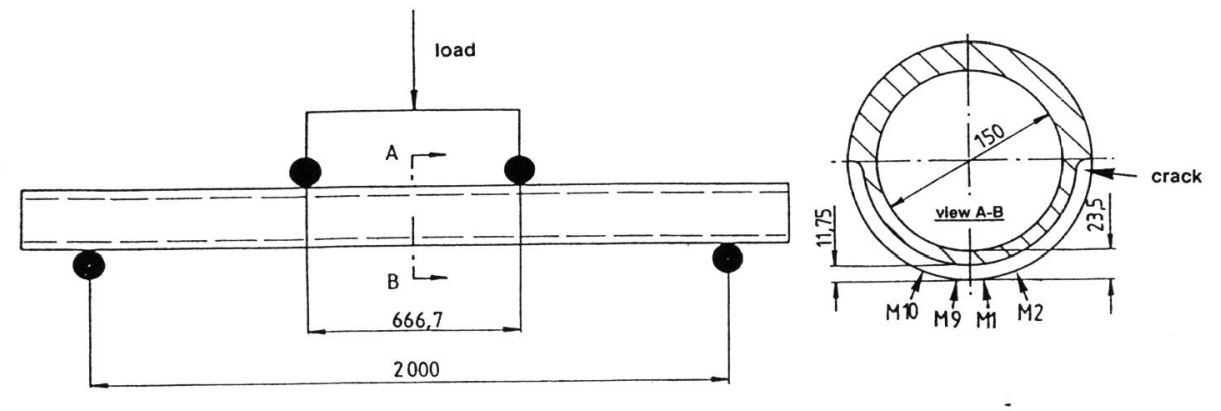

Fig. 5. Schematic diagram of the bending apparatus for fatigue crack growth experiments with tubes

For the calculation of $\Delta \mathrm{K}_{\mathrm{I}}$ in a tube with a surface crack in circumferential direction, the several approximation methods from literature were considered:

a) Calculation by Newman and Raju (1981) for a plate with a surface crack in 4 point bending:

b) equ. (2) with Folias factor for a semi-elliptical surface crack;

c) same as b, but with additional consideration of small scale yielding (methods b and $c$ were described by Schwalbe, 1980);

d) EPRI-solution (Kumar et al. 1984) for an axisymmetric crack in tension (cp. ch. 3.1);

e) finite element calculation of Grebner and Strathmeier (1985) for a surface crack in tension.

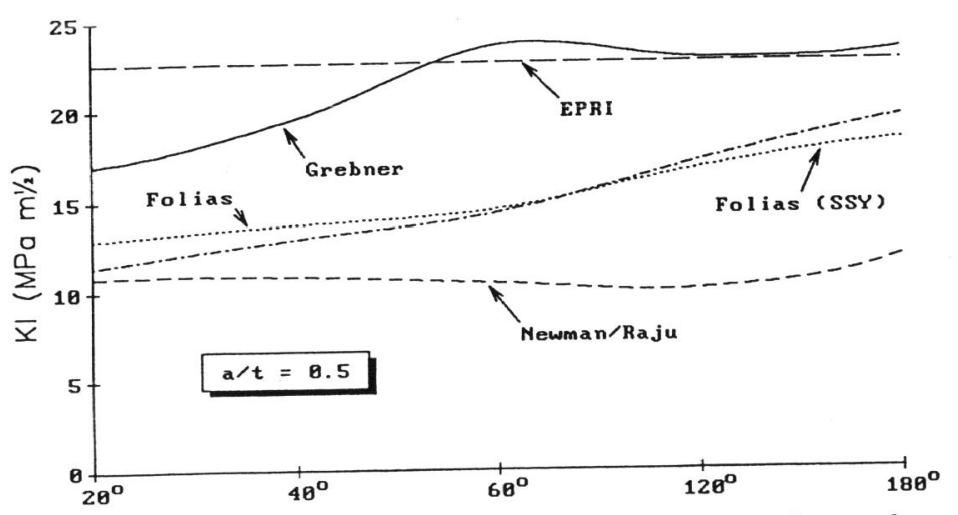

6ig. Calculated stress intensity factor for tube with circumferential cracks loaded in bending

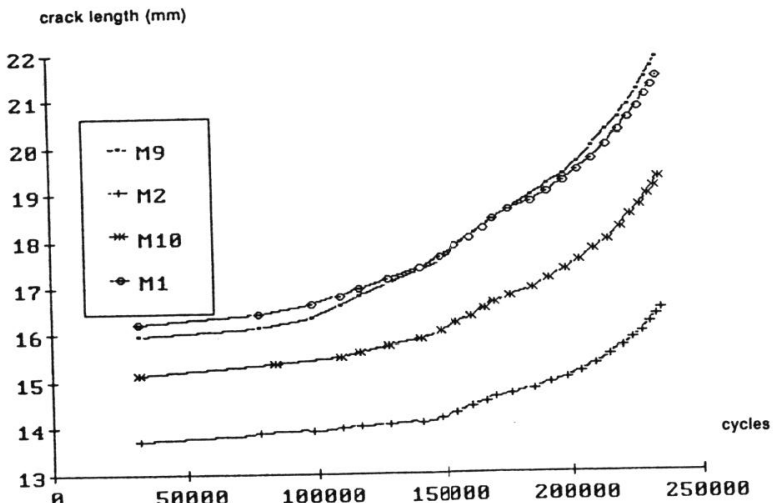

Fig. 7. Progression of crack depth during a fatigue experiment (tube in 4 point bending

Figure 6 shows a comparison of calculated $K_{I}$-values for all 5 methods, Figure 6 shows a comparison $180^{\circ}$, and a load of $100 \mathrm{kN}$.

\section{Results}

Figure 7 shows the crack length as a function of cycles at the four potential measuring points (cp. Fig. 5). In the first phase of evaluation, the $\mathrm{da} / \mathrm{dN}$ vs. $\Delta \mathrm{K}_{\mathrm{I}}$-curve only for the regime between 60 and $90 \%$ crack depth was calculated. The results for the two measuring points with the highest bending moments (M1 and M9) agree very well, and hence the same symol was used in the following diagrams.

The calculation of $\Delta \mathrm{K}_{\mathrm{T}}$ was done by means of the five equations mentioned The calculation above, and da/dN vs.

The agreement with the results of standard specimens is poor for all calculation methods. But most of them give conservative results. Method "d" and "e", by which the real crack shape is described best, are in rather good agreement. For these methods the same Paris-exponent is found as for the standard specimens, but the crack propagation rate ls significantly forer. The poor agreement for methods "a" to "c" is thought to be due to the bad description of the rom loading conditions (no conto be due calculation considering the actual crack front and loading condition is under progress. 

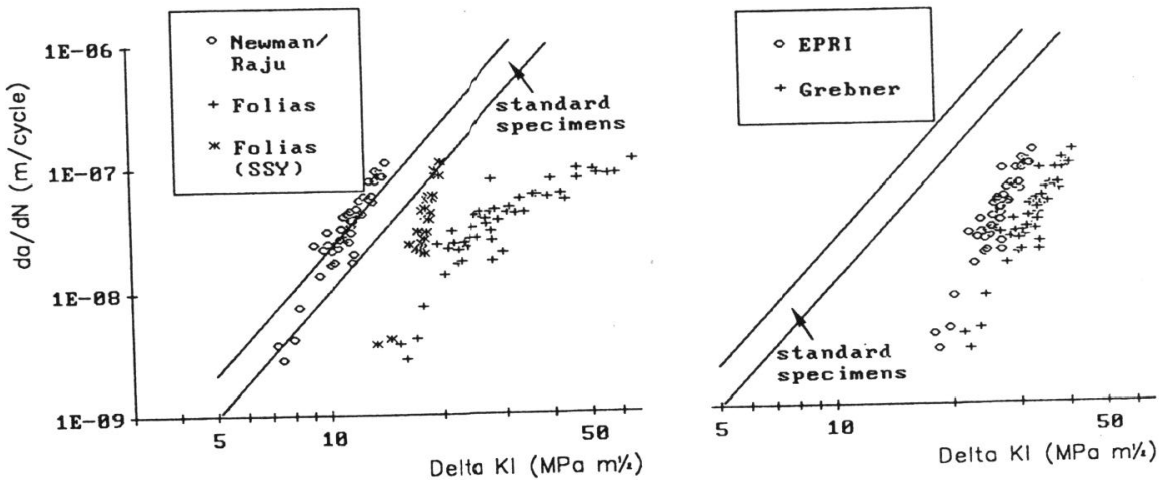

Fig. 8. crack growth rate da/dN vs. loading parameter $\mathrm{K}_{\mathrm{I}}$, calculated by several approximation methods

CONCLUSIONS

The aim of transferring fracture mechanics data for Alloy 800 from standard specimens to components was reached only partially. If the energy rate integral C* is used as a loading parameter, the creep crack growth rates in tubes (loaded by internal pressure and tension) can be described on the base of CT specimen results. The description by means of $\mathrm{K}_{\mathrm{I}}$ is unsatisfactory. The transferability of fatigue crack growth data the methods to in four point bending, was less anreement of standard specimens calculate $\mathrm{K}_{\mathrm{I}}$ give
and tubes is poor.

\section{REFERENCES}

Grebner, H. and U. Strathmeier (1985). Spannungsintensitätsfaktoren fur Grebner, $H$. and U. Strathmeier (1985). S. Werkstofftechnik 16, 442-426. Kumar v et al. (1984). Advances in elastic-plastic fracture analysis. EPRI-Report NP-3607.

Newman, J. C and I.S. Raju (1981). An empirical stress-intensity factor Newman, J. C. and l.s. Ra ju (185-192.

Riedel, H. and W. Wagner (1984). Creep crack growth in NIMONIC $80 \mathrm{~A}$ and in $1 \mathrm{Cr}-1 / 2$ Mo-steel. Proc. of the $6 \mathrm{th}$ Int. Conf. on Fracture (ICF 6).

Rödig, M, M. Pfaffelhuber, H. Nickel and F. Schubert (1987). Experiments on the transferability of fatigue crack growth data at temperatures above $700{ }^{\circ} \mathrm{C}$. Proceedings of the 9 th SMIRT Conference.

Rodig, M., R. Kienzler, H. Nickel and F. Schubert (1988). Fatigue and creep crack growth in methane reformer tubes at temperatures above $700^{\circ} \mathrm{C}$. Nuclear Engineering and Design 108 , Schwalbe, K. H. (1980)
Verlag, Munchen/Wien.

Part of the investigations reported in this paper have been carried out under the contract of the German Feder respor Minister for the Environment, Nature Conservateness of the information or for the due considerresponsibility for the correctness, accuracy, and con the authors want to thank the company Hochtemperatur-Reaktorbau $\mathrm{GmbH}$ for their support. 